Patients Have Families

By Prof. Henry B. Richardson. Pp. xx + 408. (New York: Commonwealth Fund; London: Oxford University Press, 1945.) 16s. 6d. net.

$\mathrm{T}$ HIS book is based on an investigation carried out by representatives of the medical profession and social services in New York into the relationship between stresses and strains in a family and the occurrence of disease. Members of the group were taken from the Faculties of Public Health, Medicine and Psychiatry of the Medical College at Cornell, the New York Hospital and its social service department and from the family case work service and the educational nursing department of the Community Service Society. They acted under the general direction of the author.

The aims of this 'family study' were, first, to study the interrelation between illness and the family situation and so try to counteract the present tendency of the medical profession to concentrate on disease alone, apart from the individual and his family; and secondly, to explore the best methods of co-operation between the different services in the treatment of difficult, unstable, family situations.

The importance of the above professions working together is shown, as are the methods by which close co-operation was achieved but, owing to the difference in the public health services in other countries, only the broad outlines of these methods would be of value outside the United States of America. On the other hand, the details given of fifteen families studied, analysed and treated should be of great interest everywhere in showing the different types of family situations met and their associated diseases, as well as the value of pooling the resources of the various services in obtaining a complete picture of the patient and his family. The book offers a stimulating impetus in the march towards a vigorous health policy.

K. M. Hawkins.

\section{Tables of Elementary Functions}

(In English and German.) By Fritz Emde. Pp. xii + 181. (Ann Arbor, Mich. : J. W. Edwards, 1945.) (Copyright vested in the Alien Property Custodian, 1944: first published in Leipzig and Berlin, 1940.) 3.20 dollars.

THrs book is yet another example of a photolithoprint reproduction made in the United States by authority of the Alien Property Custodian. The original work, compiled by Emde at Stuttgart and published in 1940, is presented in conjunction with its English translation. Much of the information to be found in the 1933 Jahnke-Emde is included, with certain modifications ; broadly speaking, those tables of elementary functions which were omitted from the 1938 edition and later found their way back into the American reprint.

Within its scope of 180 pages, there is a wealth of valuable material. First, a table of powers followed by factor-tables of numbers from 119 to 9997 ; secondly, a section dealing with tabular solution of quadratic, cubic and quartic equations; thirdly, a galaxy of tabulated results connected with the circular and hyperbolic functions (for both real and complex variables); and finally, a collection of tables and formulæ, dealing with special transcendental functions, such as $e^{-x^{2}}$, Planck's radiation function, Langevin's function and Chebyshev's polynomials.

It would be impossible and indeed unfair to attempt to give any sort of detailed description of its contents in a short review. It must suffice to say that the author has succeeded in producing yet another most valuable aid to mathematicians and computers alike. The book is well bound, clearly reproduced and would constitute a valuable addition to any scientific library.

J. H. Pearoe.

Les derniers progrès de la chimie

Par Prof. Roger Simonet. Dix-septième édition. Pp. 244. (Paris: Editions Balzac, 1944.) 75 francs.

7 HE present small book is written in an interesting style and covers a range of subjects not easily accessible outside patent specifications or large and expensive treatises. The first chapter deals with chemical synthesis, the second with catalysis (containing many interesting facts not usually met with), and the remaining pages deal with the structure of matter and radioactivity, the chemistry of hydrogen, the synthesis of ammonia and nitric acid, methanol, synthetic petrol, perfumes, dyes, drugs, rayon, plastics, artificial textiles, biochemistry, vitamins, hormones, 'poison gases', electrochemistry, and light alloys. The book contains, for its size, an astonishing amount of information, and gives an excellent survey of modern chemical industry. The paper is poor and in the copy reviewed some pages of text were blurred, but as a war publication it puts some other countries rather in the shade. At a time when so much rubbish is published, such a book deserves high praise, and the call for a səventeenth edition points to a demand for educational literature which is noteworthy.

\section{Vegetable Matter in the New South Wales Wool Clip}

By E. J. Milthorpe. Pp. vii +60 . (Sydney : Central Wool Committee Testing House, 1943.) $21 s$.

7 HIS little book is excellently produced and illustrated. Its main purpose is to acquaint wool appraisers with the common fruits and other parts of plants which become caught up in the fleece of sheep in New South Wales, and it has a map to show from which parts of the State the common 'burrs' of wool come. It is surprising, considering the richness of the New South Wales flora, that so few species of plants contaminate wool; the book describes only forty-five species, and many of these are unimportant.

Apart from its use to the wool specialist, the book is interesting as a catalogue of a specialized form of plant dispersal; a form so efficient that some of the seeds from New South Wales germinate among the wool mills of the English Midlands.

\section{E. Ashry.}

\section{The Groundwork of Volumetric Analysis}

By A. J. Mee. (Dent's Modern Science Series.) Pp. viii +72 . (London: J. M. Dent and Sons, Ltd., 1945.) 2s. $6 d$.

TR. MEE'S book provides a course in practical 1 volumetric analysis suitable for examinations of school certificate stage, covering acid-alkali, permanganate, and silver nitrate titrations. The experimental details and the methods of calculation are very fully and clearly described, and typical examples are worked out. The book is an excellent introduction to the subject and can be recommended as fulfilling its purpose, which is to help the beginner to understand the practice and theory of volumetric analysis. Many examples for exercise, with answers, add to the usefulness of the book. 